\title{
The attitudes of Korean cancer patients, family caregivers, oncologists, and members of the general public toward advance directives
}

\author{
Bhumsuk Keam • Young Ho Yun • Dae Seog Heo • Byeong Woo Park • Chi-Heum Cho • \\ Sung Kim • Dae Ho Lee • Soon Nam Lee • Eun Sook Lee • Jung Hun Kang • \\ Si-Young Kim • Jung Lim Lee • Chang Geol Lee • Yeun Keun Lim • Sam Yong Kim • \\ Jong Soo Choi • Hyun Sik Jeong • Mison Chun
}

Received: 7 May 2012 / Accepted: 10 December 2012 /Published online: 22 December 2012

(C) Springer-Verlag Berlin Heidelberg 2012

\begin{abstract}
Purpose The purpose of this study was to investigate Korean attitudes toward advance directives (ADs) among cancer patients, family caregivers, oncologists, and the general public.
\end{abstract}

B. Keam • D. S. Heo $(\bowtie)$

Department of Internal Medicine and Cancer Research Institute,

Seoul National University Hospital, 101 Daehak-ro, Jongno-gu,

Seoul 110-744, Republic of Korea

e-mail: heo1013@snu.ac.kr

Y. H. Yun $(\bowtie)$

Seoul National University College of Medicine,

103 Daehak-ro, Jongno-gu,

Seoul 110-799, Republic of Korea

e-mail: lawyun08@gmail.com

B. W. Park

Department of Surgery, Yonsei University Medical Center,

Yonsei University College of Medicine, Seoul, South Korea

C.-H. Cho

Department of Obstetrics and Gynecology, School of Medicine, Keimyung University, Daegu, South Korea

S. Kim

Department of Surgery, Samsung Medical Center, Sungkyunkwan

University School of Medicine, Seoul, South Korea

D. H. Lee

Department of Internal Medicine, Asan Medical Center,

University of Ulsan College of Medicine, Seoul, South Korea

S. N. Lee

Department of Internal Medicine, Ewha Womans University

School of Medicine, Seoul, South Korea

E. S. Lee

Division of Convergence Technology, Center for Breast Cancer, Research Institute and Hospital, National Cancer Center, Goyang, South Korea
Methods A multicenter survey study explored the attitudes of participants to ADs, and hospice-palliative care (HPC) was conducted. A total of 1,242 cancer patients, 1,289 family caregivers, 303 oncologists, and 1,006 members of the general public participated in the survey.

\section{J. H. Kang}

Departments of Internal Medicine, Post-Graduate Medical School, Gyeongsang National University, Jinju, South Korea

\section{S.-Y. Kim}

Department of Medical Oncology/Hematology,

Kyung Hee University Hospital, Seoul, South Korea

J. L. Lee

Department of Hematooncology, Fatima Hospital, Daegu,

South Korea

C. G. Lee

Department of Radiation Oncology, Yonsei Cancer Center,

Yonsei University College of Medicine, Seoul, South Korea

Y. K. Lim

Department of Internal Medicine, Kwangju Christian Hospital, Kwangju, South Korea

\section{S. Y. Kim}

Department of Internal Medicine, Chungnam National University College of Medicine, Daejeon, South Korea

J. S. Choi

Department of Hematooncology, Gangneung Asan Hospital, Asan University School of Medicine, Gangneung, South Korea

H. S. Jeong

Departments of Internal Medicine, Pohang Sunlin Hospital, Pohang, South Korea

M. Chun Department of Radiation Oncology, Ajou University School of Medicine, Suwon, South Korea 
Results The majority of patients, family caregivers, oncologists, and general public agreed with the necessity of ADs. However, oncologists regard "when became terminal status" as an optimal timing for completion of ADs (52.2\%), while other groups regard earlier periods as it. More than $95 \%$ oncologist answered that cardiopulmonary resuscitation and mechanical ventilator are necessity items for $\mathrm{ADs}$ form, while around $70 \%$ of other groups answered so. Multivariate analysis revealed that several factors including agreement with terminal disclosures and a positive attitude toward HPC were independently associated with necessity of ADs.

Conclusions We found that attitudes toward ADs among cancer patients, family caregivers, oncologists, and the general public were significantly different. Our study also suggests that favorable attitudes toward comfort end-of-life care and HPC are keys that influence the perceived need for ADs.

Keywords Advance directives $\cdot$ Attitude $\cdot$ Hospice-palliative care

\section{Introduction}

Advance directives (ADs) document patients' preferences towards end-of-life planning, based on patient autonomy and self-determination. ADs are designed to protect patient autonomy based on the belief that patients who lose decision making capacity are more likely to receive the care they want if they choose a surrogate decision maker, document their wishes in advance, or both [1]. ADs allow patients to choose how they should be treated in the event that they lose the ability to make their own medical decisions. Absence of ADs may lead to unwanted aggressive care after decision making ability has been lost [2], and this unwanted aggressive care has been associated with poorer quality of life and quality of care [3]. Thus, ADs are an essential part of comprehensive care near the end-of-life [4].

However, only 20 to $40 \%$ of patients in oncology units complete ADs on admission [5, 6]. Completion rate of ADs has not even change after the passage of the Patient SelfDetermination Act in 1990 [7] and has remained relatively low in USA [8]. ADs are not actively used in Korea [9], where significant proportions of cancer patients receive chemotherapy up to end-of-life $[10,11]$. Furthermore, no consensus has been reached regarding effective strategies toward the active use of ADs, as well as optimal timing for completing ADs.

Various issues, including lack of information regarding ADs [12], negative perception [13], lack of communication [14], and physicians' reluctance [13, 15], could inhibit the implementation of ADs. Hence, in order to encourage the use of ADs and to devise effective strategies aimed at promoting the completion of ADs, compressive understandings regarding the attitudes toward ADs and end-of-life issues by the different people are strongly warranted. However, to date, published studies have focused on the attitudes of patients toward ADs [12,16], and completion of ADs [17]. There are discrepancies in attitude toward end-of-life care and planning among patients, family caregivers, and physicians [18-22]. Few studies have directly compared the attitudes of patients, family caregivers, physicians, and members of the general public toward ADs. Differences in perceptions towards ADs would be obstacles toward their institutionalization and incorporation into law. For example, in USA, the federal Patient Self-Determination Act which aimed facilitating the use of AD seems to fail because the act and policy had not reflected complex issues happened in real medico-social field [8]. Accordingly, the purpose of this study was to investigate Korean attitudes toward ADs among cancer patients, family caregivers, oncologists, and members of the general public. In addition, we attempted to identify factors associated with a favorable perception toward ADs, and finally, we suggest a strategy to encourage the use of ADs.

\section{Materials and methods}

\section{Participants}

Seventeen general hospitals participated in this multicenter survey study, which was designed to identify issues related to hospice-palliative care (HPC) and ADs. Between 2008 and 2009, we surveyed four groups: cancer patients, family caregivers, oncologists, and members of the general Korean population. A total of 1,378 cancer patients, 1,335 of their family caregivers, 374 oncologists, and 1,325 members of the general public were consecutively enrolled. Details of the participant selection process and of eligibility criteria were described in our prior report [23]. In brief, details of the participants were given in the following paragraph.

A total of 17 representative general hospitals of Korea were selected; cancer patients of these hospitals were surveyed. Oncologists at 17 hospitals (16 general hospitals and Korea's National Cancer Center) were asked to identify cancer patients at outpatient clinics. Cancer patients were eligible to participate if they were $\geq 20$ years old, able to fill out the questionnaire, communicate with an interviewer, understand the goals of the study, and provide informed consent. Those not well enough to complete the questionnaire, communicate with an interviewer, or understand the study well enough to provide informed consent were excluded. For each patient included in the study, the main caregiver who provided the patient with the most assistance 
was given information about the study and interviewed by a trained interviewer. In addition, 374 oncologists working at the 17 participant hospitals were requested to complete the questionnaire. Face-to-face interviews for patients, caregiver, and oncologists were conducted by well-trained interviewer, using a structured questionnaire. In order to reduce inter-observer variation, all interviewers received special education for questionnaire more than $6 \mathrm{~h}$, and we performed pilot test and cross check for each interviewer.

Members of the general Korean population aged 2070 years old, distributed over the 17 city and local districts, were selected according to the standard sampling guidelines of the 2005 Census of Korea by Korea National Statistical Office. At each site, we constructed the sample in two strata (by age and sex), according to the guidelines of. Starting with 1,325 randomly selected residential telephone numbers, we obtained our final sample using a probabilityproportional-to-size technique, which is a widely recommended method for obtaining a representative national sample $[23,24]$. Sample size of general population who reflect whole nation was determined based on calculated based on sampling guidelines of Korea National Statistical Office. This survey was conducted over the telephone by Korea Research Inc. using a structured questionnaire by professional interviewers. The interviewers were received special training and adequate education for this survey.

Finally, a total of 1,242 cancer patients, 1,289 of their family caregivers, 303 oncologists, and 1,006 members of the general public constituted the study cohort. Detailed exclusion process and reasons for declining survey were described in our prior report [23].

All study subjects were provided with information concerning the study objectives and scope and voluntarily agreed to participate. The study was approved by the Institutional Review Board at each of the all 17 participating hospitals.

\section{Survey}

A structured questionnaire was developed specifically for this study to explore the attitudes of participants to ADs. The questionnaire requested the following: (1) demographic information: age, sex, relationship to patient, level of education, income, and religion; (2) the opinion of the participants regarding necessity of ADs (very necessary, necessary, unnecessary, and very unnecessary), the optimal timing of ADs (when healthy, diagnosed, in the terminal stage, or impending death), necessary items for ADs form (cardiopulmonary resuscitation, mechanical ventilator, antibiotics, hemodialysis, and nutritional support); (3) opinions on the disclosure of terminal status, HPC, the withdrawal of futile life-sustaining treatment, and euthanasia. A total of 29 questions were asked to each group for obtaining their opinion regarding not only $\mathrm{ADs}$ but also overall concept for HPC. Identical questions were put to cancer patients, family caregivers, oncologists, and members of the general public. Additional questions concerning experiences of hospice and preterminal care were put to oncologists. Patients were assured that their responses would not be shared with their oncologists.

\section{Statistics}

Questionnaire responses were compared using the Chisquare test. Univariate logistic regression models were used to test associations with attitudes toward ADs. Multivariate analysis was performed using the forward stepwise procedure to fit a logistic regression model using an entry level of 0.05. All statistical tests were two-sided, and significance was accepted for $P$ values of $<0.05$. Statistical analyses were performed using STATA statistical software version 11.0 (STATA, College Station, TX, USA).

\section{Results}

Discrepancies in attitudes toward advance directives

Demographic data were collected from all patients, and the characteristics of all 3,840 study subjects are summarized in Table 1. Median age of the study subjects was 47 years, and cancer patients were older than members of the other three study groups. Significant discrepancies in attitudes toward necessity and timing for ADs were found between cancer patients, family caregiver, oncologists, and the general public (Table 2). The majority of patients, family caregivers, oncologists, and general public agreed with the necessity of ADs $(96.7 \%$ of oncologists, $94.9 \%$ of the general public, $93.0 \%$ of patients, and $92.9 \%$ of family caregivers). In terms of necessary items for ADs form, more than $95 \%$ oncologists answered that items regarding cardiopulmonary resuscitation $(97.0 \%)$ and mechanical ventilator $(95.3 \%)$ would be included in ADs form and need to be clarified by document. In other groups, around $70 \%$ of subjects answered that cardiopulmonary resuscitation $(72.8 \sim 81.5 \%)$ and mechanical ventilator $(72.6 \sim 77.2 \%)$ are necessary items for ADs form. Relatively lower proportion of oncologist answered that antibiotics (35.6\%), hemodialysis (65.5\%), and artificial nutrition (53.5\%) are necessary items for ADs form. Regarding the necessary items for ADs form, there were no significant differences between the three groups.

Optimal timing for the completion of ADs also differed by group. More than half of oncologists (52.2\%) answered that "when became terminal status" is the optimal time for completing ADs, whereas only one third of the other groups 
Table 1 Characteristics of the study subjects $(N=3,840)$

\begin{tabular}{|c|c|c|c|c|c|}
\hline & & $\begin{array}{l}\text { Cancer patients } \\
N=1,242\end{array}$ & $\begin{array}{l}\text { Family caregivers } \\
N=1,289\end{array}$ & $\begin{array}{l}\text { Oncologists } \\
N=303\end{array}$ & $\begin{array}{l}\text { General public } \\
N=1,006\end{array}$ \\
\hline \multirow[t]{2}{*}{ Sex } & Male & $588(47.4)$ & $483(37.5)$ & $247(81.5)$ & $507(50.4)$ \\
\hline & Female & $653(52.6)$ & $806(62.5)$ & $56(18.5)$ & 499 (49.6) \\
\hline \multirow[t]{3}{*}{ Age group } & $\leq 39$ & $161(13.0)$ & $527(41.1)$ & $152(50.7)$ & $483(48.0)$ \\
\hline & $40-49$ & $355(28.8)$ & $330(25.7)$ & $89(29.7)$ & $249(24.8)$ \\
\hline & $\geq 50$ & $718(58.2)$ & $426(33.2)$ & $59(19.6)$ & $274(27.2)$ \\
\hline \multirow[t]{3}{*}{ Education completion } & $\leq$ Middle school & $288(23.5)$ & $156(12.1)$ & $0(0.0)$ & $128(12.7)$ \\
\hline & High school & $523(42.6)$ & $467(36.3)$ & $0(0.0)$ & $383(38.1)$ \\
\hline & College or beyond & $415(33.8)$ & $663(51.5)$ & $303(100.0)$ & $495(49.2)$ \\
\hline \multirow[t]{3}{*}{ Monthly income $\left(\mathrm{US}^{\mathrm{a}}{ }^{\mathrm{a}}\right)$} & $<1,500$ & $371(30.8)$ & $244(19.2)$ & & 255 (27.9) \\
\hline & $1,500-3,000$ & $459(38.2)$ & $507(40.0)$ & & $352(38.5)$ \\
\hline & $>3,000$ & $373(31.0)$ & $517(40.8)$ & $303(100.0)$ & $307(33.6)$ \\
\hline \multirow[t]{5}{*}{ Religion } & Christianity & $396(32.1)$ & $418(32.6)$ & $121(40.1)$ & $272(27.0)$ \\
\hline & Buddhism & $297(24.1)$ & $316(24.6)$ & $21(7.0)$ & $209(20.8)$ \\
\hline & Catholicism & $138(11.2)$ & $148(11.5)$ & $69(22.8)$ & $127(12.6)$ \\
\hline & Others & $41(3.3)$ & $35(2.7)$ & $0(0.0)$ & $22(2.2)$ \\
\hline & None & $360(29.2)$ & $365(28.5)$ & $91(30.1)$ & $376(37.4)$ \\
\hline \multirow[t]{4}{*}{ Relationship to patients } & Spouse & & $324(25.2)$ & & \\
\hline & Child & & $515(40.0)$ & & \\
\hline & Sibling & & $106(8.2)$ & & \\
\hline & Other relatives & & $341(26.5)$ & & \\
\hline
\end{tabular}

${ }^{\mathrm{a}} \mathrm{US} \$ 1=1,000$ Korean Won

thought so, and $27.0 \%$ of general public answered that optimal timing for the completion of ADs is "when healthy" (Table 2). In addition, members of the four groups showed statistically significant but modest differences in terms of the necessary items for ADs and the necessity of providing an explanation of HPC.

Univariate and multivariate logistic regression analysis

We performed univariate and multivariate logistic regression analysis to identify factors associated with necessity for ADs. Several factors including age, education, attitude toward terminal illness, and attitudes toward HPC were found to be significantly associated with attitudes to ADs (Table 3). Table 4 presents the multivariable logistic regression model results, which were adjusted for multiple factors simultaneously. Younger age, higher education, agreement with the disclosure of terminal illness, a positive attitude toward the withdrawal of futile life-sustaining treatment, a positive attitude toward active pain control in terminal cancer patients, and a positive attitude towards HPC were found to be independently associated with necessity of ADs. Logistic regression analysis was also used to identify factors associated with necessity of ADs on a group-by-group basis; the observed trends were similar to those found by multivariable logistic regression (data not shown).

\section{Discussion}

In this study, we found that attitudes toward ADs among cancer patients, family caregivers, oncologists, and the general public were significantly different, in terms of regarding the optimal timing of AD completion and necessity of items in ADs form. Members of the four study groups also expressed different opinions about ADs. Oncologists and members of the general public were more likely agreed with the necessity of ADs. Multivariate analysis revealed that nine factors, including a younger age, higher education, agreement with the disclosure of terminal illness, and favorable attitudes toward active pain control and HPC were independently associated with necessity of ADs.

In our results, oncologists tends to regard when became terminal status as an optimal timing for completion of ADs, while other groups earlier periods - when healthy or "when diagnosed as cancer"-as it. More than $95 \%$ oncologist answered that cardiopulmonary resuscitation and mechanical ventilator are necessity items for ADs form and need to be clarified by document, while around $70 \%$ of other groups answered so. One possible interpretation would be that oncologists seem to expect ADs being as a judgment criteria for medical decision, while other groups seems to regard ADs as a will which containing values about end-oflife. Oncologists and general public groups more often 
Table 2 Attitudes toward advance directives: discrepancies between cancer patients, family caregivers, oncologists, and general public

\begin{tabular}{|c|c|c|c|c|c|}
\hline & & $\begin{array}{l}\text { Cancer patients } \\
N=1,242\end{array}$ & $\begin{array}{l}\text { Family caregivers } \\
N=1,289\end{array}$ & $\begin{array}{l}\text { Oncologists } \\
N=303\end{array}$ & $\begin{array}{l}\text { General public } \\
N=1,006\end{array}$ \\
\hline \multirow{4}{*}{ Necessity of $\mathrm{ADs}^{\mathrm{a}}$} & Strongly necessary & $348(28.1)$ & $355(27.6)$ & $99(32.7)$ & $393(39.9)$ \\
\hline & Necessary & $804(64.9)$ & $839(65.3)$ & $194(64.0)$ & $541(55.0)$ \\
\hline & Unnecessary & $79(6.4)$ & $87(6.8)$ & $10(3.3)$ & $38(3.9)$ \\
\hline & Strongly unnecessary & $8(0.6)$ & $4(0.3)$ & $0(0.0)$ & $12(1.2)$ \\
\hline \multirow[t]{4}{*}{ Optimal timing for completing $\mathrm{ADs}^{\mathrm{a}}$} & When healthy & $217(17.6)$ & $221(17.3)$ & $45(15.0)$ & $266(27.0)$ \\
\hline & When diagnosed as cancer & $364(29.5)$ & $377(29.5)$ & $60(19.9)$ & $335(33.9)$ \\
\hline & When became terminal status & $459(37.2)$ & $485(38.0)$ & $157(52.2)$ & $313(31.7)$ \\
\hline & Impending death & $193(15.7)$ & $193(15.1)$ & $39(13.0)$ & $73(7.4)$ \\
\hline \multicolumn{6}{|l|}{ Necessary items for ADs form } \\
\hline \multirow[t]{2}{*}{ (1) Cardiopulmonary resuscitation ${ }^{a}$} & Necessary & $844(72.8)$ & $961(78.4)$ & $292(97.0)$ & $786(81.5)$ \\
\hline & Unnecessary & $316(27.2)$ & $265(21.6)$ & $9(3.0)$ & $178(18.5)$ \\
\hline \multirow[t]{2}{*}{ (2) Mechanical ventilator ${ }^{\mathrm{a}}$} & Necessary & $836(72.6)$ & $944(77.4)$ & $287(95.3)$ & $758(77.2)$ \\
\hline & Unnecessary & $315(27.4)$ & $275(22.6)$ & $14(4.7)$ & $224(22.8)$ \\
\hline \multirow[t]{2}{*}{ (3) Antibiotics use ${ }^{a}$} & Necessary & $808(70.8)$ & $906(75.2)$ & $101(35.6)$ & $776(80.7)$ \\
\hline & Unnecessary & $334(29.2)$ & $299(24.8)$ & $183(64.4)$ & $185(19.3)$ \\
\hline \multirow[t]{2}{*}{ (4) Hemodialysis ${ }^{a}$} & Necessary & $760(66.9)$ & $882(73.7)$ & $190(65.5)$ & $742(77.8)$ \\
\hline & Unnecessary & $376(33.1)$ & $315(26.3)$ & $100(34.5)$ & $212(22.2)$ \\
\hline \multirow[t]{2}{*}{ (5) Artificial nutrition and hydration ${ }^{a}$} & Necessary & $873(75.5)$ & $953(78.7)$ & $153(53.5)$ & $793(81.7)$ \\
\hline & Unnecessary & $284(24.5)$ & $258(21.3)$ & $133(46.5)$ & $178(18.3)$ \\
\hline \multirow[t]{2}{*}{ (6) Explanation for $\mathrm{HPC}^{\mathrm{a}}$} & Necessary & $996(84.8)$ & $1070(87.1)$ & $252(85.1)$ & $880(90.8)$ \\
\hline & Unnecessary & $178(15.2)$ & $159(12.9)$ & $44(14.9)$ & $89(9.2)$ \\
\hline
\end{tabular}

$A D s$ advance directives, $H P C$ hospice and palliative care

${ }^{\mathrm{a}}$ Chi-square $P<0.001$

agreed with necessity of ADs than patients or family caregivers; however, this difference was modest even statistically significant. Large sample size can lead to statistical overpower, and interpretation of the result should be based on not statistical significance but clinical significance.

Our multivariate analysis results can suggest that the promotion of favorable attitudes toward HPC would influence positively regarding the necessity of ADs. Although ADs are important tools that assist cancer patients facing end-of-life respecting patients' autonomy [4], completion rates are still low $[5,6,8]$. In order to implement an $\mathrm{AD}$ system successfully, we need to comprehensively understand attitudes towards ADs and barriers to ADs and construct an appropriate strategy based on these findings. A number of studies have addressed barriers to the implementation of ADs, and have identified clinicians' reluctance to discuss the topic, because of personal discomfort, lack of familiarity with suitable alternatives to aggressive treatment, lack of time for discussions, the belief that patients and families do not want such discussions, and the belief that ADs discussions are not needed [13, 15, 18, 25]. Alano et al. [17] analyzed barriers and factors that influenced the completion of ADs and concluded that seven factors predicted $\mathrm{AD}$ completion: being asked to complete an $\mathrm{AD}$, having someone explain the importance of ADs, the belief that a completed $\mathrm{AD}$ would lead to relief from suffering, a history of major surgery, "having never heard of or received information about ADs," a female gender, and age.

Previous studies on attitudes towards ADs in patients [17, 26], family caregivers [27], physicians [28, 29], nurses [30], and in the members of general public [31] have been reported. Few studies have addressed the notion that attitudes towards ADs differ among relevant population subgroups [32-34]. Sahm et al. [34] reported that the patients, healthy control, nursing staff, and physicians did not essentially differ in terms of their attitudes towards ADs; however, three meaningful differences were identified: (1) cancer patients more often expressed an intention to write an advance directive, (2) most people (excepting physicians) are unaware of the possibility of appointing health care proxies, and (3) patients did not fear abuse by relatives as much as the other groups. Blondeau et al. [32] reported that physicians' attitudes towards ADs were less positive than patients' attitudes, which contradicts our results. Accordingly, to our findings, oncologists most favored HPC and ADs, 
Table 3 Factors related to "necessity of advance directives": Univariate logistic regression analysis

\begin{tabular}{|c|c|c|c|c|}
\hline \multirow[t]{2}{*}{ Factors } & \multirow[t]{2}{*}{ Variables } & \multicolumn{3}{|c|}{ Necessity of ADs (yes) } \\
\hline & & OR & $95 \% \mathrm{CI}$ & $P$ value \\
\hline \multirow[t]{4}{*}{ Group } & Patients & 1 (ref) & & 0.026 \\
\hline & Family & 0.99 & 0.73 to 1.34 & 0.953 \\
\hline & Doctor & 2.21 & 1.14 to 4.31 & 0.020 \\
\hline & General public & 1.41 & 0.99 to 2.02 & 0.060 \\
\hline \multirow[t]{2}{*}{ Sex } & Male & 1 (ref) & & \\
\hline & Female & 1.15 & 0.88 to 1.49 & 0.311 \\
\hline \multirow[t]{2}{*}{ Age, years } & $20-49$ & 1 (ref) & & \\
\hline & $50+$ & 0.57 & 0.44 to 0.75 & $<0.001$ \\
\hline \multirow[t]{2}{*}{ Education completed } & High school & 1 (ref) & & \\
\hline & College or beyond & 1.99 & 1.51 to 2.63 & $<0.001$ \\
\hline \multirow[t]{2}{*}{ Religiousness } & Nonreligious & 1 (ref) & & \\
\hline & Religious & 0.92 & 0.69 to 1.23 & 0.578 \\
\hline \multirow[t]{2}{*}{ Monthly income (US\$) } & $<2,000$ & 1 (ref) & & \\
\hline & $\geq 2,000$ & 1.27 & 0.97 to 1.67 & 0.086 \\
\hline \multirow[t]{2}{*}{ Disclosure of terminal illness } & Agree & 1 (ref) & & \\
\hline & Disagree & 0.68 & 0.50 to 0.95 & 0.021 \\
\hline \multirow[t]{2}{*}{ Attitude toward withdrawal of futile life-sustaining treatment } & Agree & 1 (ref) & & \\
\hline & Disagree & 0.39 & 0.28 to 0.54 & $<0.001$ \\
\hline \multirow[t]{2}{*}{ Attitude toward passive euthanasia } & Agree & 1 (ref) & & \\
\hline & Disagree & 0.54 & 0.42 to 0.71 & $<0.001$ \\
\hline \multirow[t]{2}{*}{ Attitude toward active euthanasia } & Agree & 1 (ref) & & \\
\hline & Disagree & 0.83 & 0.63 to 1.08 & 0.168 \\
\hline \multirow[t]{2}{*}{ Attitude toward physician-assisted suicide } & Agree & 1 (ref) & & \\
\hline & Disagree & 0.73 & 0.55 to 0.96 & 0.023 \\
\hline \multirow[t]{2}{*}{ Attitude toward active pain control for terminal cancer patients } & Agree & 1 (ref) & & \\
\hline & Disagree & 0.34 & 0.25 to 0.47 & $<0.001$ \\
\hline \multirow[t]{2}{*}{ Are you willing to use HPC unit if necessary? } & Yes & 1 (ref) & & \\
\hline & No & 0.33 & 0.24 to 0.44 & $<0.001$ \\
\hline \multicolumn{5}{|l|}{ Attitude and perception toward HPC } \\
\hline \multirow[t]{2}{*}{ (1) HPC is despair } & Agree & 1 (ref) & & \\
\hline & Disagree & 1.87 & 1.38 to 2.54 & $<0.001$ \\
\hline \multirow[t]{2}{*}{ (2) HPC has professionalism } & Agree & 1 (ref) & & \\
\hline & Disagree & 0.60 & 0.45 to 0.79 & $<0.001$ \\
\hline \multirow[t]{2}{*}{ (3) HPC is better place than usual care unit for terminal cancer patients } & Agree & 1 (ref) & & \\
\hline & Disagree & 0.55 & 0.42 to 0.73 & $<0.001$ \\
\hline \multirow[t]{2}{*}{ (4) HPC is against fulfilling family's duty } & Agree & 1 (ref) & & \\
\hline & Disagree & 2.08 & 1.51 to 2.87 & $<0.001$ \\
\hline \multirow[t]{2}{*}{ (5) HPC is against fulfilling doctors' duty } & Agree & 1 (ref) & & \\
\hline & Disagree & 2.18 & 1.58 to 3.01 & $<0.001$ \\
\hline (6) HPC hasten patients' death & Agree & 1 (ref) & & \\
\hline & Disagree & 1.68 & 1.2 to 2.34 & 0.002 \\
\hline (7) HPC is better choice than aggressive chemotherapy for terminal cancer patients & Agree & 1 (ref) & & \\
\hline & Disagree & 0.56 & 0.43 to 0.73 & $<0.001$ \\
\hline Obligation to explain HPC & Agree & 1 (ref) & & \\
\hline & Disagree & 0.34 & 0.25 to 0.46 & $<0.001$ \\
\hline Do you willingly pay for additional medical insurance premium for hospice care? & Yes & 1 (ref) & & \\
\hline & No & 0.47 & 0.35 to 0.63 & $<0.001$ \\
\hline
\end{tabular}


Table 3 (continued)

Factors

Variables

Necessity of ADs (yes)

\begin{tabular}{lllll} 
& & OR & $95 \%$ CI & $P$ value \\
\hline Set up "deathbed"a in hospitals with $>500$ beds & Agree & 1 (ref) & & \\
& Disagree & 0.27 & 0.2 to $0.37 \quad<0.001$ \\
\hline
\end{tabular}

$O R$ odd ratio, $C I$ confidence interval

${ }^{a}$ Deathbed is a special room for a patient who refuses cardiopulmonary resuscitation or intensive care unit, in order to have death with dignity as patient's wishes.

and in general, the attitudes of family caregivers and cancer patients coincided.

This study had several limitations. First, we conducted the survey in person for patients, family caregivers, and oncologists, but by telephone in the general public, which may lessen the validity of the comparisons made. Face-toface interviewer may observe understandability and reliability more precisely than telephone interviewers. However, we have given special training to telephone interviewers, and we used a model based on an identical study design and identical questionnaires to overcome this shortcoming. Second, we enrolled only Korean participants, and there is a cross-cultural difference regarding ADs [35]. Thus, our results have limitation for being generalized to other cultures. Despite these limitations, to our best knowledge, this study was conducted using the largest cohort number, and it comprehensively identified factors associated with ADs in the four study groups.

In conclusion, to make shared decisions regarding endof-life planning, we would recognize that attitudes toward ADs can differ among patients, family caregivers, oncologists, and members of the general public. In addition, it was also found that negative attitudes toward futile aggressive care and favorable attitudes toward HPC were independently associated with a preference for ADs. This study suggests that (1) to reduce difference in attitudes toward ADs between each group and (2) to obtain favorable attitude toward HPC might be considered a cornerstone strategy for the implementation of $\mathrm{ADs}$ programs and facilitating $\mathrm{AD}$ use. In addition, comprehensive social movement including institutional innovation, policy interventions, public education, and professional guidelines might be warranted.

Table 4 Factors related to "necessity of advance directives": multivariate logistic regression analysis

\begin{tabular}{|c|c|c|c|c|}
\hline \multirow[t]{2}{*}{ Factor } & \multirow[t]{2}{*}{ Variables } & \multicolumn{3}{|c|}{ Necessity of ADs (yes) } \\
\hline & & OR & $95 \% \mathrm{CI}$ & $P$ value \\
\hline \multirow[t]{2}{*}{ Age, years } & $50+$ & 1 (ref) & & \\
\hline & $20-49$ & 1.54 & 1.12 to 2.08 & 0.006 \\
\hline \multirow[t]{2}{*}{ Education completed } & High school & 1 (ref) & & \\
\hline & College or beyond & 1.69 & 1.22 to 2.34 & 0.002 \\
\hline \multirow[t]{2}{*}{ Disclosure of terminal illness } & Disagree & 1 (ref) & & \\
\hline & Agree & 1.96 & 1.33 to 2.94 & 0.001 \\
\hline \multirow[t]{2}{*}{ Attitude toward withdrawal of futile life-sustaining treatment } & Disagree & 1 (ref) & & \\
\hline & Agree & 1.79 & 1.22 to 2.63 & 0.003 \\
\hline \multirow[t]{2}{*}{ Attitude toward active pain control for terminal cancer patients } & Disagree & 1 (ref) & & \\
\hline & Agree & 2.00 & 1.37 to 2.94 & $<0.001$ \\
\hline \multirow[t]{2}{*}{ HPC is against fulfilling doctors' duty } & Agree & 1 (ref) & & \\
\hline & Disagree & 1.47 & 1.01 to 2.17 & 0.046 \\
\hline \multirow[t]{2}{*}{ Obligation to explain HPC } & Disagree & 1 (ref) & & \\
\hline & Agree & 2.13 & 1.49 to 3.03 & $<0.001$ \\
\hline \multirow[t]{2}{*}{ Do you willingly pay for additional medical insurance premium for HPC? } & No & 1 (ref) & & \\
\hline & Yes & 1.49 & 1.06 to 2.08 & 0.022 \\
\hline \multirow[t]{2}{*}{ Set up "deathbed" in hospitals with $>500$ beds } & Disagree & 1 (ref) & & \\
\hline & Agree & 2.63 & 1.82 to 3.70 & $<0.001$ \\
\hline
\end{tabular}


Acknowledgments This work was supported by the 2008 Korean National Cancer Control Program by the Ministry for Health, Welfare and Family Affairs, Korea, and partially by grant no. 0710730-3 from the National Cancer Center, Korea.

Conflict of interest The authors have no competing interests to declare.

\section{References}

1. Brown BA (2003) The history of advance directives. A literature review. J Gerontol Nurs 29:4-14

2. Harrington SE, Smith TJ (2008) The role of chemotherapy at the end of life: "when is enough, enough?". JAMA 299:2667-2678

3. Earle CC, Landrum MB, Souza JM, Neville BA, Weeks JC, Ayanian JZ (2008) Aggressiveness of cancer care near the end of life: is it a quality-of-care issue? J Clin Oncol 26:3860-3866

4. Pautex S, Herrmann FR, Zulian GB (2008) Role of advance directives in palliative care units: a prospective study. Palliat Med 22:835-841

5. Landry FJ, Kroenke K, Lucas C, Reeder J (1997) Increasing the use of advance directives in medical outpatients. J Gen Intern Med $12: 412-415$

6. Degenholtz HB, Rhee Y, Arnold RM (2004) Brief communication: the relationship between having a living will and dying in place. Ann Intern Med 141:113-117

7. Teno JM (2004) Advance directives: time to move on. Ann Intern Med 141:159-160

8. Yates JL, Glick HR (1997) The failed patient self-determination act and policy alternatives for the right to die. J Aging Soc Pol 9:2950

9. Kim S, Hahm KH, Park HW, Kang HH, Sohn M (2010) A Korean perspective on developing a global policy for advance directives. Bioethics 24:113-117

10. Keam B, Oh DY, Lee SH, Kim DW, Kim MR, Im SA, Kim TY, Bang YJ, Heo DS (2008) Aggressiveness of cancer-care near the end-of-life in Korea. Jpn J Clin Oncol 38:381-386

11. Yun YH, Kwak M, Park SM, Kim S, Choi JS, Lim HY, Lee CG, Choi YS, Hong YS, Kim SY, Heo DS (2007) Chemotherapy use and associated factors among cancer patients near the end of life. Oncology 72:164-171

12. Silveira MJ, DiPiero A, Gerrity MS, Feudtner C (2000) Patients' knowledge of options at the end of life: ignorance in the face of death. JAMA 284:2483-2488

13. Feeg VD, Elebiary H (2005) Exploratory study on end-of-life issues: barriers to palliative care and advance directives. Am J Hosp Palliat Care 22:119-124

14. Sapir R, Catane R, Kaufman B, Isacson R, Segal A, Wein S, Cherny NI (2000) Cancer patient expectations of and communication with oncologists and oncology nurses: the experience of an integrated oncology and palliative care service. Support Care Cancer 8:458-463

15. Curtis JR, Patrick DL, Caldwell ES, Collier AC (2000) Why don't patients and physicians talk about end-of-life care? Barriers to communication for patients with acquired immunodeficiency syndrome and their primary care clinicians. Arch Intern Med 160:1690-1696

16. Nolan MT, Bruder M (1997) Patients' attitudes toward advance directives and end-of-life treatment decisions. Nurs Outlook $45: 204-208$
17. Alano GJ, Pekmezaris R, Tai JY, Hussain MJ, Jeune J, Louis B, El-Kass G, Ashraf MS, Reddy R, Lesser M, Wolf-Klein GP (2010) Factors influencing older adults to complete advance directives. Palliat Support Care 8:267-275

18. Quill TE (2000) Perspectives on care at the close of life. Initiating end-of-life discussions with seriously ill patients: addressing the "elephant in the room". JAMA 284:2502-2507

19. Yun YH, Kwon YC, Lee MK, Lee WJ, Jung KH, Do YR, Kim S, Heo DS, Choi JS, Park SY (2010) Experiences and attitudes of patients with terminal cancer and their family caregivers toward the disclosure of terminal illness. J Clin Oncol 28:1950-1957

20. Oh DY, Kim JE, Lee CH, Lim JS, Jung KH, Heo DS, Bang YJ, Kim NK (2004) Discrepancies among patients, family members, and physicians in Korea in terms of values regarding the withholding of treatment from patients with terminal malignancies. Cancer 100:1961-1966

21. Clayton JM, Butow PN, Tattersall MH (2005) When and how to initiate discussion about prognosis and end-of-life issues with terminally ill patients. J Pain Symptom Manag 30:132-144

22. Dow LA, Matsuyama RK, Ramakrishnan V, Kuhn L, Lamont EB, Lyckholm L, Smith TJ (2010) Paradoxes in advance care planning: the complex relationship of oncology patients, their physicians, and advance medical directives. J Clin Oncol 28:299-304

23. Yun YH, Han KH, Park S, Park BW, Cho CH, Kim S, Lee DH, Lee SN, Lee ES, Kang JH, Kim SY, Lee JL, Heo DS, Lee CG, Lim YK, Choi JS, Jeong HS, Chun M (2011) Attitudes of cancer patients, family caregivers, oncologists and members of the general public toward critical interventions at the end of life of terminally ill patients. CMAJ 183:E673-E679

24. Levy PS, Lemeshow LS (2009) Sampling of populations: methods and applications, 4th edn. Wiley, New York

25. Lo B, Quill T, Tulsky J (1999) Discussing palliative care with patients. ACP-ASIM End-of-Life Care Consensus Panel. American College of Physicians-American Society of Internal Medicine. Ann Intern Med 130:744-749

26. Douglas R, Brown HN (2002) Patients' attitudes toward advance directives. J Nurs Scholarsh 34:61-65

27. Yoshida S, Hirai K, Morita T, Shiozaki M, Miyashita M, Sato K, Tsuneto S, Shima Y (2011) Experience with prognostic disclosure of families of Japanese patients with cancer. J Pain Symptom Manag 41:594-603

28. Masuda Y, Fetters MD, Hattori A, Mogi N, Naito M, Iguchi A, Uemura K (2003) Physicians's reports on the impact of living wills at the end of life in Japan. J Med Ethics 29:248-252

29. Davidson KW, Hackler C, Caradine DR, McCord RS (1989) Physicians' attitudes on advance directives. JAMA 262:24152419

30. Blondeau D, Lavoie M, Valois P, Keyserlingk EW, Hebert M, Martineau I (2000) The attitude of Canadian nurses towards advance directives. Nurs Ethics 7:399-411

31. Akabayashi A, Slingsby BT, Kai I (2003) Perspectives on advance directives in Japanese society: a population-based questionnaire survey. BMC Med Ethics 4:E5

32. Blondeau D, Valois P, Keyserlingk EW, Hebert M, Lavoie M (1998) Comparison of patients' and health care professionals' attitudes towards advance directives. J Med Ethics 24:328-335

33. McAdam JL, Stotts NA, Padilla G, Puntillo K (2005) Attitudes of critically ill Filipino patients and their families toward advance directives. Am J Crit Care 14:17-25

34. Sahm S, Will R, Hommel G (2005) Attitudes towards and barriers to writing advance directives amongst cancer patients, healthy controls, and medical staff. J Med Ethics 31:437-440

35. Con A (2008) Cross-cultural considerations in promoting advance care planning in Canada. BC Cancer Agency, Vancouver 